\title{
R3 - OTIMIZAÇÃO DO PROCESSO DE OBTENÇÃO DE ANTICORPOS CAPRINOS ANTI-IgG HUMANA UTILIZADOS NA PRODUÇÃO DE IMUNORREATIVOS PARA DIAGNÓSTICO
}

Priscila Muniz da Paz, Edinea Pastro Mendes, Hilton Jorge Nascimento e Jose Godinho da Silva-Junior.

Objetivo: Este trabalho está relacionado ao melhoramento das etapas metodológicas envolvidas na produção da imunoglobulina anti-IgG humana a ser usada no kit de diagnóstico da Leishmaniose humana.

Métodos: As amostras de soro policlonal caprino anti-IgG humana foram submetidas a diferentes concentrações de sulfato de amônio (SA) para determinar a condição adequada de precipitação. Em seguida o precipitado foi solubilizado e submetido à dessalinização em cromatografia de exclusão molecular na matriz Sephadex G25. A fração proteica recuperada foi quantificada pelo método de Folin-Lowry modificado e analisada por SDS-PAGE 12,5\%. Visando a seleção da coluna cromatográfica de troca iônica mais apropriada para a purificação do anticorpo em questão foram testadas as matrizes Hitrap ANX, Hitrap Q FF, DEAE Hicap, TMAE Hicap, DMAE Hicap e Poros HQ50 - todas contendo $1 \mathrm{~mL}$ de leito cromatográfico. Os eluentes e as condições cromatográficas foram as mesmas para todas as colunas. Visando a determinação da capacidade de ligação dinâmica das colunas Poros HQ, DEAE Hicap scout e TMAE Scout - aquelas que apresentaram os melhores resultados usou-se uma fração anti-IgG humana purificada na coluna Poros HQ 50.

Resultados: A melhor condição para a precipitação de imunoglobulina caprina anti- $\operatorname{IgG}$ humana foi de 30\% de saturação de sulfato de amônio (1,2 M). As colunas Hitrap ANX, DEAE Hicap, TMAE Hicap e DMAE Hicap apresentaram frações que efluíram no volume morto das colunas. As colunas Hitrap Q FF e Poros HQ50 apresentaram perfis cromatográficos similares, mostrando significativa resolução entre a fração de $\operatorname{IgG}$ e o pico de albumina. 
Conclusão: O uso da matriz cromatográfica Sephadex G25 em uma coluna XK 50 $(5 \mathrm{~cm} \times 30 \mathrm{~cm})$ com o propósito de dessalinização do soro caprino anti-IgG humana precipitado com $30 \%$ de sulfato de amônio mostrou-se eficiente. Dentre as colunas cromatográficas previamente selecionadas, em um total de 7 colunas, aquelas que mostraram a melhor resolução para a purificação - separação da albumina da IgG de cabra (anti - IgG humana), foram as colunas Poros HQ 50 e Hitrap Q FF. A Poros HQ mostrou a maior capacidade de ligação da matriz (Binding Dynamic Capacity) dentre as colunas testadas, a saber, Poros HQ 50, DEAE Hicap e TMAE Hicap. Os resultados auferidos neste trabalho são auspiciosos no sentido de propor futuramente a substituição da coluna de DEAE Sephacel, classicamente utilizada na purificação de anticorpos, levando-se em conta não só a sua resolução, como também sua alta capacidade de ligação à amostra em tela. Ademais, podemos salientar que a coluna de perfusão cromatográfica Poros HQ 50 pode operar com um fluxo de pelo menos 10 vezes maior do que o tradicionalmente usado com a coluna de DEAE Sephacel, resultando tal fato em uma economicidade de tempo (high-throughput). 